\title{
Posttraumatic Adrenal Hematoma a Case Report and Literature Review
}

Diarra Daouda $^{1 *}$, Salihou Abdoulfatihi ${ }^{1}$, Dzota Johane ${ }^{1}$, Laoudihy Dalale ${ }^{1}$, Chbani Kamilia ${ }^{1}$, Salam Siham ${ }^{1}$, El Ouzidane Lahcen $^{1}$ ${ }^{1}$ Pediatric Radiology Service Abderrahim Harouchi Children's Hospital, Ibn Rochd University Hospital Center of Casanblanca,
Hassan II University of Casablanca, Morocco

DOI: $10.36347 /$ sjmcr.2022.v10i01.010

| Received: 27.11.2021 | Accepted: 02.01.2022 | Published: 29.01.2022

*Corresponding author: Diarra Daouda

Pediatric Radiology Service Abderrahim Harouchi Children's Hospital, Ibn Rochd University Hospital Center of Casanblanca, Hassan II University of Casablanca, Morocco

\section{Abstract}

Post-traumatic adrenal hematoma is a difficult to diagnose condition with rare but severe complications. Posttraumatic adrenal hematoma occurs in up to $2 \%$ of patients with abdominal trauma. Only CT scans performed during lesion assessments of violent thoracoabdominal trauma can confirm the diagnosis. Symptomatology is often masked by associated visceral or parietal injuries. Standard biological examinations are generally of little help. We describe a case of a 12-year-old child who presented with a right adrenal hematoma after a road traffic accident (MVA), associated with a peritoneal effusion and a fracture of the right sacral fin as well as a fracture of the right pubic ischium.

Keywords: Adrenal hemorrhage, Computed tomography, Thoracic and abdominal traumas.

Copyright $\odot 2022$ The Author(s): This is an open-access article distributed under the terms of the Creative Commons Attribution 4.0 International License (CC BY-NC 4.0) which permits unrestricted use, distribution, and reproduction in any medium for non-commercial use provided the original author and source are credited.

\section{INTRODUCTION}

Adrenal hematoma of post-traumatic origin concerns between 0.03 and $2 \%$ of cases of abdominal trauma $[1,2]$. Because of its anatomy and deep location, the adrenal gland is not very susceptible to direct trauma, but the anatomical characteristics of its arterial network, particularly at the corticomedullary junction, make it susceptible to hematoma and venous thrombosis during high-energy trauma [3, 4]. The severity is quite variable and depends on the size of the hematoma and the uni- or bilateral nature of the lesion. We report a case of a post-traumatic right adrenal hematoma.

\section{Case Presentation}

This is a 12-year-old child victim of a traffic accident (MVA) was hospitalized for abdominopelvic trauma. The clinical examination noted a more marked abdominal defense in the right hypochondrium associated with pelvic pain.

Abdominal ultrasound showed a moderate peritoneal effusion in the right iliac fossa, without visualization of traumatic injury to the liver, spleen, pancreas and kidneys. The abdominal CT scan confirmed the existence of a hematoma of the right adrenal gland (swollen and spontaneously hyperdense aspect of the right adrenal gland) (Fig 1), a peritoneal effusion (Fig 2) and a fracture of the right sacral fin (Fig 3), of the right ischio pubic ramus (Fig 4). The clinical course was satisfactory with strict bed rest and analgesic and better management of the bone fractures in the orthopedic and trauma surgery department.

Ultrasound monitoring at one week showed regression of the right adrenal hematoma, with complete regression on the follow-up scan performed two months later.

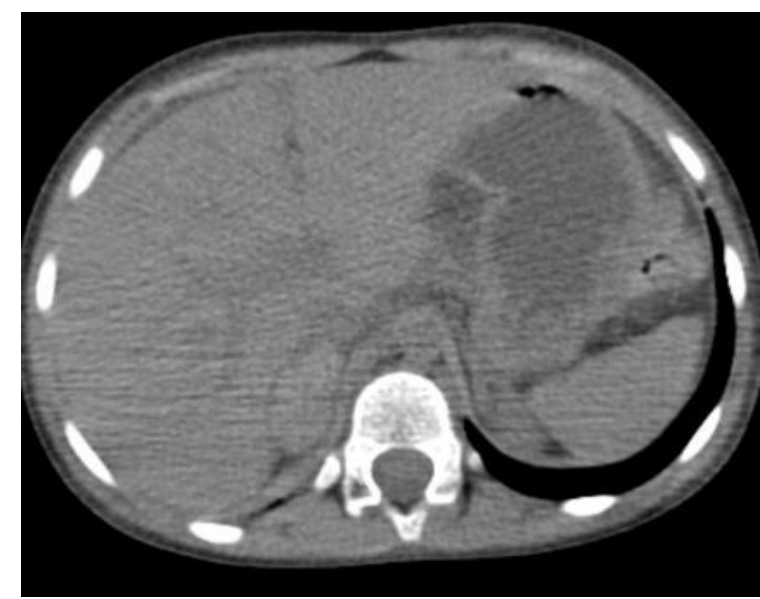

Fig 1: Abdominal CT scan without PDC injection in axial section: swollen and spontaneously 


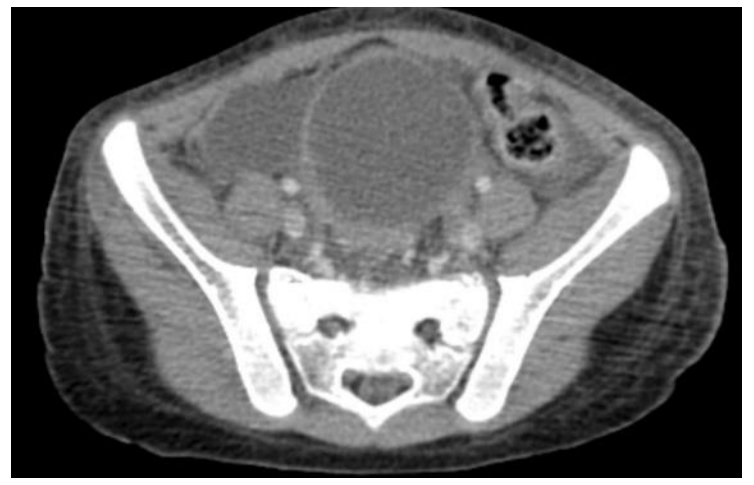

Fig 2: Peritoneal effusion of the right iliac fossa hyperdense aspect of the right adrenal gland

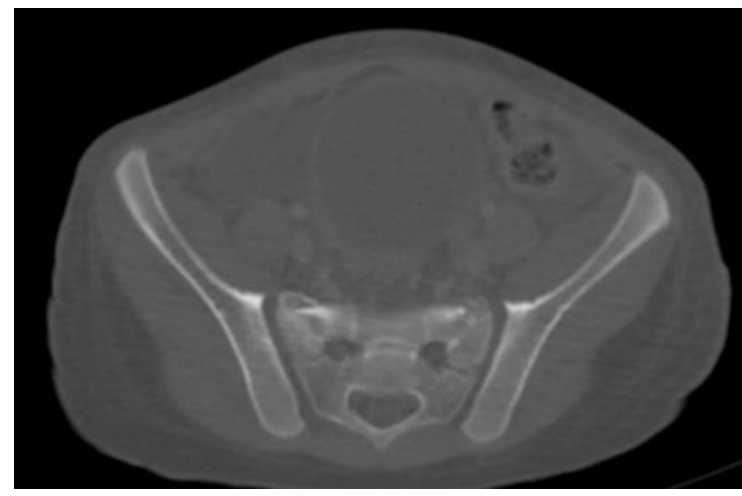

Fig 3: Scanner axial section bone window: right sacral fin fracture

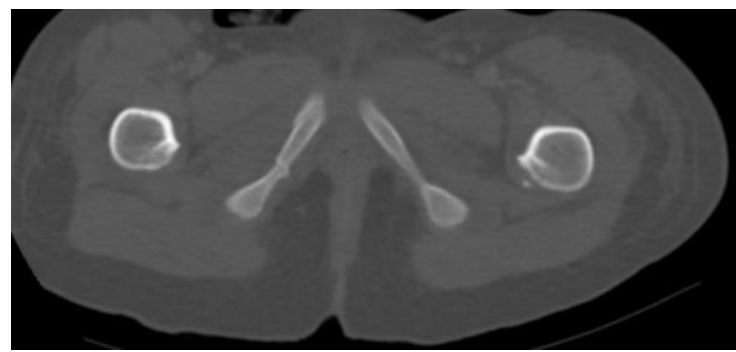

Fig 4: Fracture of the right ischiopubic branch

\section{DiscusSiON}

Post-traumatic adrenal hematoma is a rare pathology and their frequency is estimated between 0.03 and $2 \%$ of patients with severe abdominal trauma $[1,2]$. It may be unilateral in $85 \%$ of cases, with a clear right-sided predominance in $75-85 \%$ of cases, in contrast to nontraumatic adrenal hematomas, which are bilateral in $75 \%$ of cases $[2,5]$. The morbidity of adrenal trauma is high (estimated at $10-15 \%$ ), whereas mortality (less than 10\%) is mainly related to acute adrenal insufficiency and the severity of associated trauma $[2,6]$.

From a pathophysiological point of view, the traumatic mechanism at the origin of an adrenal hematoma is complex and subject to several hypotheses (contusion, compression) and it seems that the violence of the shock is not always the determining factor. Various factors may favour the appearance of adrenal haemorrhage: stress, disorders of haemostasis, whether primary or iatrogenic, and finally pre-existing lesions of the adrenal gland [1].

The diagnosis is therefore based on the association of a suggestive thoracoabdominal trauma, abdominal pain and signs of hemorrhage, but it is made difficult by the aspecific nature of the clinical and biological symptomatology. Radiological examinations are used to make the diagnosis of adrenal hematoma. Abdominal ultrasound, which is non-invasive and inexpensive, allows a rapid initial assessment of the suprarenal hematoma, which is characterized by a mass of mixed echostructure with a predominantly hyperechoic fluid component and retroperitoneal location. Ultrasound of the adrenal gland, however, has its limitations: its sensitivity is $79 \%$ and its specificity is $61 \%[7,8]$.

Abdominal computed tomography (CT) is the reference examination for the exploration of adrenal lesions $[1,2,9,10]$. Usually the image is spontaneously hyperdense during the early phase and takes on the appearance of a cocoon opacity. Finally, the CT examination will evaluate the size, volume and extension to the peritoneum of the hematoma and will ensure the integrity of the kidney and the absence of underlying adrenal lesions. The majority of posttraumatic adrenal hematomas have a favorable evolution. The presence of clinical and biological abnormalities should raise the suspicion of a local complication (visceral compression, thrombosis of the inferior vena cava, superinfection), hemorrhage or endocrine complication. The most serious complication, acute adrenal insufficiency, occurs more frequently with bilateral hemorrhages and should be considered in the presence of a state of hypovolemic shock with a septic appearance that is refractory to the usual treatments $[1,11,12]$.

Conservative treatment (strict bed rest and analgesic treatment) should be favored to preserve the adrenal gland as much as possible and to avoid possible surgical complications which may threaten adrenal function in the long term. Surgery is only justified in case of diagnostic doubt or complications threatening the functional or vital prognosis.

\section{Conclusion}

Post-traumatic adrenal hematoma is an uncommon pathology, and CT scan is the reference examination to confirm the diagnosis. It is usually associated with other thoracoabdominal lesions in patients who have suffered violent trauma.

\section{REFERENCES}

1. Burks, D. W., Mirvis, S. E., \& Shanmuganathan, K. (1992). Acute adrenal injury after blunt abdominal trauma: CT findings. AJR. American journal of roentgenology, 158(3), 503-507. 
2. Rana, A. I., Kenney, P. J., Lockhart, M. E., McGwin Jr, G., Morgan, D. E., Windham III, S. T., \& Smith, J. K. (2004). Adrenal gland hematomas in trauma patients. Radiology, 230(3), 669-675.

3. Granry, J. C., Houet, J. F., \& Delhumeau, A. (1989, January). Hématomes des surrénales et héparine. In Annales françaises d'anesthésie et de réanimation (Vol. 8, No. 6, pp. 650-655). Elsevier Masson.

4. Rao, R. H., Vagnucci, A. H., \& Amico, J. A. (1989). Bilateral massive adrenal hemorrhage: early recognition and treatment. Annals of Internal Medicine, 110(3), 227-235.

5. Gómez, R. G., McAninch, J. W., \& Carroll, P. R. (1993). Adrenal gland trauma: diagnosis and management. The Journal of trauma, 35(6), 870874.

6. Dinc, H. A. S. A. N., Şimşek, A., Ozyavuz, R. A. S. İ. N., Ozgür, G. K., \& Gümele, H. R. (2002). Endovascular treatment of massive retroperitoneal haemorrhage due to inferior adrenal artery injury: A case report. Acta Radiologica, 43(3), 326-328.

7. Gore, R. M., Callen, P. W., \& Filly, R. A. (1982). Displaced retroperitoneal fat: sonographic guide to right upper quadrant mass localization. Radiology, 142(3), 701-705.

8. Swobodnik, W., Swobodnik, W., Altwein, J. E., \& Basting, R. F. (1989). Atlas d'anatomie échographique. Flammarion Médecine Sciences

9. Murphy, B. J., Casillas, J., \& Yrizarry, J. M. (1988). Traumatic adrenal hemorrhage: radiologic findings. Radiology, 169(3), 701-703.

10. Wilms, G., Marchal, G., Baert, A., Adisoejoso, B., \& Mangkuwerdojo, S. (1987). CT and ultrasound features of post-traumatic adrenal hemorrhage. Journal of computer assisted tomography, 11(1), 112-115.

11. Baccot, S., Tiffet, O., Bonnot, P., Perrot, L., \& Cuilleret, J. (2000, April). Hémorragie surrénalienne bilatérale post-traumatique. À propos d'un cas avec insuffisance surrénale aiguë. In Annales de chirurgie (Vol. 125, No. 3, pp. 273 275). Elsevier Masson.

12. Feuerstein, B., \& Streeten, D. H. (1991). Recovery of adrenal function after failure resulting from traumatic bilateral adrenal hemorrhages. Annals of internal medicine, 115(10), 785-786. 